\title{
Kelsey's Story
}

Kevin Roberg

J Pediatr Pharmacol Ther 2005;10:4-7

I would like to share with you the perspective of a parent who has been through the medication error experience. I am going to talk about patient safety vis-à-vis the experiences that my wife, Cindy, and I had with three separate institutions. Two of them were pediatric care institutions and one was an adult and pediatric care institution. I am here as a health care consumer, to share a story and highlight the issues health care consumers deal with. These are real issues, ones that we need to be concerned about, and ones we need to effectively deal with.

I guess I am not your typical parent of an ill child because I spent the past 30 years as a health care executive. I started as a clinic administrator and then went for work with over 15 outpatient institutions across the country, helping them implement Deming's quality assurance process. I've also run two major health maintenance organizations (HMO), two national pharmacy benefit management companies, and am currently a health care venture capitalist.

My daughter, Kelsey, was born August 1, 1984. The first ten months of her life were typical and non-eventful. That changed when Cindy took Kelsey to a well-baby check in early 1985. She had noticed that Kelsey had a distended stomach. The doctor-who happened to be my boss and a pediatric oncologist-diagnosed the condition as bilateral Wilms' tumor. At the time we were told that although this was a very serious condition, Wilms' tumor was very treatable and the doctor felt that we had

Address correspondence to: Kevin Roberg, 30245 East Horseshoe Lake Road Merrifield, MN 56465, e-mail: kevinr@delphiventures.com (C) 2005 Pediatric Pharmacy Advocacy Group diagnosed the condition fairly early. In fact, today the survival rate is over $95 \%$.

Like most parents, we were shocked because you always think this is going to happen to someone else. The first days and weeks that followed the diagnosis can best be described as overwhelming. For months, we were in and out of the hospital and in and out of doctor's offices. We were at the mercy of the health care system. We felt that it was good, in a way. We needed to focus on Kelsey and take care of our two other kids. We needed someone to care for our daughter, and we relied on the health system to do so effectively. There was a comfort that the skilled men and women of the health care institutions we were dealing with would take good care of our daughter and she would be safe in that environment.

In addition to the early weeks being a shock, they were also very educational. We learned a lot about Wilms' tumor-about what is "favorable" about it (it is very treatable) but it is still a cancer. Unfortunately, Kelsey's tumor was bilateral, so there was a lot of bad. Right away, within the first week, one kidney was taken out and part of the other kidney was removed.

We also learned a lot about the health care system. Since I lived in the health care system world I thought I knew a lot about it, but I learned more. We learned a lot about drugs, and we discovered that drugs can have really good benefits, but also can have some very bad side effects-and if not prescribed correctly can have some significantly bad results. We also had our first experiences with safety problems. We noticed that medications that should have been taken with food were given to her without food and vice versa. We questioned why different dosages were given, and we found out 
later that some were mistakes. We found that the medications were often changed, and we learned that disagreements among oncologists are not uncommon. Scans that were supposed to be taken were not. Several allergic reactions were narrowly avoided, and the documentation was poor.

It was not as though the providers were not good people; that the physicians did not want to practice good medicine; that the nurses did not want to take good care of the kids at these institutions and do the very best they could do. But it is a very complicated system, and it gets more complicated every day. Furthermore, this very complicated system did not possess the necessary tools to effectively manage this complexity.

In the early stages of Kelsey's illness, even though there were errors, there were not any that I would call life-threatening or serious-at least that we were aware of. We felt that she was in a safe haven; this was a good pediatric hospital where the people who were taking care of her were trained, talented and wanted to do their very best. Thus, we did not feel the need to be on duty 24 hours a day, seven days a week. This was important to us because I had a job and had to also take care of our other two children, Jake and Katie. Even so, we still spent up to 18 hours with Kelsey every day that she was hospitalized. At this time her treatment was going well and our lives were moving on-so well, in fact, that I and some colleagues formed a HMO management development company and I was asked to start a HMO on the West Coast. So in June of 1986, with Kelsey's doctors' blessings we moved to the West Coast. Her doctors felt that her treatment could be carried out successfully in a pediatric specialty hospital where we would be living.

In December of that same year we finished Kelsey's original 18-month treatment of chemotherapy. At this time her doctors gave us both good news and bad news. The good news was that the tumor was almost gone; the bad news was that there was still microscopic evidence of the tumor. Her doctors were hopeful that the residual chemotherapy would take care of those microscopic cells. They also believed that they could not give her any more chemotherapy at that time since her system would probably not tolerate it well. The plan was to carefully monitor Kelsey's condition to make sure the tumor would not come back. In May 1987, her cancer reignited with a vengeance. Not only did the tumor come back in Kelsey's remaining kidney, it metastasized to the lungs. It was another shocking time for us, but we remained dedicated to beating the disease. We decided on an aggressive treatment plan of irradiation, more powerful antineoplastic agents, and more hospitalizations.

Kelsey was admitted to the hospital where she was started on a new, more potent antineoplastic drug. I think it was on the third day of treatment that the accident happened. Kelsey got her 10-mg dose in the evening when they believed she could tolerate it best. Our practice at the time was to leave the hospital at about 11 p.m. We would make sure that she took her medication and that she was doing well, and then we would go home to our two other children. The first two nights she had slept well. After the third night, Cindy came back at 9 a.m. and went into Kelsey's room. Kelsey did not look good. She did not look good at all. So Cindy went to the nurse and said, "I am really concerned about Kelsey-she looks terrible." The nurse said, "Well, didn't someone tell you?" Cindy said, "What do you mean?" The nurse answered that Cindy had better talk to the doctor. Cindy immediately feared that the doctor was going to tell her he was giving up on Kelsey because the medicine was not working.

Cindy contacted the physician, a good man and a good oncologist. He was evasive. $\mathrm{He}$ said, "Well, we had a few problems with the medication, but we think things are going to be okay." My wife, being very intuitive, called me and said, "You know what, I am not getting straight answers here and I'm really worried about this." So I called the medical director of the institution, who I knew, and said, "Listen, I want you to be straight with me. I know and you know that something happened last night. I want you to tell me what really happened last night. I am not after anybody, but I want to protect my child." That is how we found out that Kelsey was given $100 \mathrm{mg}$, not $10 \mathrm{mg}$. The doctor-and this happens every day and is probably happening right now-had meant to write down 10, and he thought he did, but when we looked at the documentation it sure looked like 100 to me. The pharmacist missed it, the 
resident missed it, the fellow missed it, the oncall physician missed it, and the nurse missed it even though the first two treatments had been $10 \mathrm{mg}$ and not 100. Again, good people trying to do a good job. Well, it almost killed her-it was a lethal dose. To add insult to injury, one of her physicians said maybe it was fortuitous that this happen because maybe it would knock the cancer out. To say the least, that did not go over well with Cindy and me.

I asked to meet with the administration and the head of the medical staff, and the first thing they said was, "Do you mind if we have our attorney there?" I said, "Yes, I mind if you have your attorney there. I am coming to you as a parent and a fellow health care executive; I am not coming to threaten litigation. What would be the appropriate reimbursement for what has happened? There isn't any. What I want is to understand what happened. I want you to understand what happened. I want to make sure it never happens again, not only to Kelsey, but to every other kid in this institution, and you should want that, too." So we met and talked about it. They described all the things that they were going to do to fix this. They were straightforward about what had happened. Somebody had mistaken $10 \mathrm{mg}$ for $100 \mathrm{mg}$. This sort of thing happens frequently because the system is flawed. It happened 15 years ago to Kelsey, and I know it still happens today.

That was the first major error that we encountered. Here is what we learned from it. We learned that we had to be at the hospital 24 hours a day, seven days a week because we needed to support the health care system ourselves. We could not be bystanders to our daughter's care-we needed to be part of it. We needed to be part of her health care provider team. Who knows our children better than their own parents? We needed to get very involved with knowing about her disease, her treatments, and the other members of her care team. It wasn't that they weren't competent; that they weren't caring; that they didn't want to do the very best job they could. They were all of that, but it is a complicated imperfect system that needs all the help it can get- and we wanted to help provide it.

We also realized that we could not be at the hospital 24 hours a day, seven days a week and stay in our West Coast location. We needed to move back to the Midwest. Not because our hospital in the Midwest was a better institution, but on the West Coast we lacked the family support system that would enable one of us to be at the hospital all day every day. We also wanted the reassurance of familiar surroundings.

By the time we had moved back to Minnesota, Kelsey had finished her radiation treatments. The main courses of chemotherapy were completed in Minnesota, and Kelsey was now ready for a bone marrow transplant. That was the good news. The bad news was that our pediatric hospital did not do bone marrow transplants, so we had to go to yet another institution. Although it was both an adult and pediatric hospital, it was a very good one, a world-class, world-renowned institution. There we had to see new physicians and new nurses, adjust to new processes, and understand even more complicated drug and medical procedures. We had to deal with a new chart, new histories, new residents, new fellows, new interns, and new medical students. We knew we would have to cope with this new environment 24 hours a day, 7 days a week, for at least 100 days.

The bone marrow was successful, and Kelsey was transferred to the pediatric floor. The bone marrow transplant unit was very different from the general pediatric floor, and we were glad to be there. However, there were errors in how medications were distributed and dispensed. Nothing major happened until the second-to-last night Kelsey was there. We tried to stay awake at night so that we could check the drugs the nurses were giving. Cindy opened her eyes to find a nurse getting ready to put something into Kelsey's IV line. "What are you doing?" asked Cindy. "Well, I am giving Kelsey her medications." This was a new nurse, by the way. "What are you giving her?" "What the doctor ordered." "What is that?" "Well, it is right here in the charts, what the doctor ordered; you don't have to be worried. You can go back to sleep." Cindy said, "No, I want to know what it is." She got up and read the order and checked the drug. It was the right medication and right dosage; unfortunately, it was the wrong patient.

So we got an early discharge and went back to our children's hospital. The cancer was gone and the blood counts were good, but because of 
the irradiation of her lungs, Kelsey developed fibrosis. So a lot of hospitalization remained. This is when the third and final major error occurred. The nurse came in at the end of the night shift. She was going to flush the IV line, and mistakenly she introduced air into the line. Kelsey had a cardiac arrest. Now my poor wife is on the phone telling me they are trying to resuscitate our little girl. This nurse had been Kelsey's nurse on and off for five years and was a fine person. She was very conscientious, but that night she was tired. She had worked multiple nights in a row and this had been a double shift for her.

Kelsey thankfully survived, went home, and went on to home care. Unfortunately, the radiation had destroyed Kelsey's lungs and she lost her battle with cancer and passed away two days before her sixth birthday. But what a battle she fought and with such spirit. We do not want that spirit to be forgotten. We learned so much from her spirit-how not to give up and not complain; how to use humor to get through the most difficult times. How perseverance can overcome almost any obstacle. I learned more from her in her short six years than from anyone else with whom I have been associated. May God continue to bless her always.

Now what did we learn through this experience? We learned that health care institutions and processes are very complicated and very imperfect. We learned that there are good people who try to do a good job, but these people need better support and better systems. As we progress with better medicines, procedures, and other medical advances, we need to make sure that we are progressing in making sure that these new technologies are delivered and provided safely. New therapeutics without appropriate safety systems achieve nothing beneficial. What good is a new blockbuster drug if we harm the patient because we don't deliver it safely? We need end-to-end medication management systems to assure the safety of all patients. We need to make sure that the right patient gets the right drug, at the right time-every time. The safety systems are out there now. We just need to invest in them. We also need to make sure that our health care institutional leaders make patient safety a top priority and not just lip service. Creating a culture of patient safety, creating a work environment where patient safety is the first priority is a must for us to make sure we "do no harm" to the patients that put their trust in us.

In one of the positions I held after Kelsey's death, I was talking with a pharmacist in one of the most prestigious health care institutions in this country about the need for a better medication management system. He said, "You know, Kevin, I don't sleep well at night. Although I think we have the best pharmacists in the country, none of us can keep up-to-date with what's going on. And I fear every night that something is going to happen." That was seven years ago, and that person still feels that way today. So I ask that each of us do whatever we can do to change our health care systems to ones that are focused first on patient safety, on doing no harm.

In ending, I would like to recognize my wife Cindy who was Kelsey's principal caregiver. This is the first time she has heard me tell this story. I am prejudiced, but she is the best mom I know. Thank you for listening to our story about our daughter Kelsey and thank you Kelsey for letting this important story be told.

ACKNOWLEDGMENT: This paper was given as the keynote address during the 2005 inaugural Stevens' Symposium, Memphis, Tennessee. 